\title{
Penerapan Teknik Prapemrosesan Smoothing Spline pada Data Hasil Pengukuran Alat Pemantau Glukosa Darah Non-Invasif
}

\author{
Putu Gita Karlina Jayanti*, Rahma Anisa*, Muhammad Nur Aidi*, Erfiani* \\ *Departemen Statistika Institut Pertanian Bogor
}

\begin{abstract}
Abstrak-Alat pemantau kadar glukosa darah noninvasif dilakukan tanpa melukai anggota tubuh. Salah satu metode pengukuran dalam bentuk kualitatif dan relatif sederhana yang digunakan karena prosesnya yang cepat dan membutuhkan biaya yang murah, yaitu Fourier Transform Infrared (FTIR). Hasil keluaran spektroskopi memungkinkan adanya pergeseran pencaran, karena objek yang sama diukur beberapa kali tidak tepat menghasilkan spektrum yang sama, sehingga dibutuhkan metode prapemrosesan untuk mereduksi permasalahan tersebut. Namun, pada beberapa kasus sulit untuk mengidentifikasi pola data yang ada, sehingga dibutuhkan suatu pendekatan nonparametrik untuk mengidentifikasi pola data yang dimiliki agar dalam proses kalibrasi model diperoleh hasil yang akurat. Smoothing Spline merupakan salah satu metode nonparametrik bersifat piecewise polynomial, yaitu suatu potongan-potongan polinom yang memiliki sifat tersegmen pada selang $k$ yang terbentuk pada titik-titik knot, sehingga memberikan fleksibilitas dalam mengkonstruksi bentuk kurva yang kita miliki. Metode Smoothing Spline menghasilkan nilai optimum ketika nilai GCV bernilai minimum pada penggunaan orde linear dengan enam belas titik knot. Nilai keragaman yang dihasilkan setelah dilakukan metode Smoothing Spline lebih kecil daripada sebelum dilakukan smoothing, hal ini mengindikasikan bahwa metode ini dapat meminimalisir pengaruh pencaran pada spektrum nilai kadar glukosa darah non-invasif. Selain itu, metode Smoothing Spline juga dapat menangkap pola kumpulan amatan dengan baik.
\end{abstract}

Kata kunci-glukosa darah; Smoothing Spline

\section{PENDAHULUAN}

\section{A. Latar Belakang}

Saat ini, banyak berkembang model kalibrasi peubah ganda untuk mengatasi permasalahan waktu dan biaya. Biaya yang dibutuhkan untuk pengadaan bahan selama persiapan sampel tidaklah sedikit. Sehingga dibutuhkan suatu pengukuran baik dalam bentuk kualitatif maupun kuantitatif untuk meminimalisir biaya serta waktu yang dibutuhkan. Salah satu metode pengukuran dalam bentuk kualitatif dan relatif sederhana karena prosesnya yang cepat dan membutuhkan biaya yang murah, yaitu Fourier Transform Infrared (FTIR). Namun keluaran yang dihasilkan FTIR ini hanya berupa spektrum besarnya nilai serapan saat sampel disinari inframerah. Ilmu yang mempelajari interaksi antara radiasi elektromagnetik dengan atom, molekul, dan materi disebut dengan spektroskopi. Spektroskopi sering digunakan untuk mengidentifikasi suatu substansi melalui penyerapan dan pemancaran suatu spektrum. Hasil keluaran spektroskopi memungkinkan adanya pergeseran pencaran, karena objek yang sama diukur beberapa kali tidak tepat menghasilkan spektrum yang sama. Hruschka (1987) menyatakan bahwa ukuran objek memiliki pengaruh yang nyata terhadap spektrum.

Spektrum yang keluar sering kali tidak sesuai dengan semestinya, hal ini terjadi karena pencaran cahaya yang disebabkan sifat fisik dan kimiawi dari objek yang diamati Arnita (2005). Pengaruh yang muncul akibat sifat fisik dan kimiawi objek dapat menyebabkan penyimpangan cahaya, ketidaklinieran pencaran, dan ketidakkonsistenan respon Blanco et al. (1998). Hal inilah yang mendasari dibutuhkannya suatu metode prapemrosesan. Metode ini dilakukan untuk mengurangi pengaruh inferensi gelombang dan noise pada data spektrum yang diperoleh agar model kalibrasi yang diperoleh lebih akurat dan stabil.

Penelitian ini akan dilakukan metode prapemrosesan untuk alat pemantau kadar glukosa darah non-invasif. Alat ini menggunakan prinsip spektroskopi dengan memanfaatkan cahaya infram- 
erah yang keluarannya berupa spektrum time domain terhadap intensitas. Menurut $\mathrm{Cen}$ and $\mathrm{He}$ (2007), beberapa metode prapemrosesan (pretreatment) yang dapat digunakan diantaranya adalah smoothing (pemulusan) dan scatter correction (koreksi pencaran). Beberapa penelitian terdahulu telah menggunakan berbagai metode koreksi pencaran dengan jenis spektroskopi yang berbeda. Salah satu metode koreksi pencaran yang sering digunakan adalah Multiplicative Scatter Correction (MSC). Arnita (2005) mengidentifikasi adanya pengaruh pencaran pada data persen transmitan senyawa aktif gingerol serbuk rimpang jahe hasil keluaran spektroskopi Fourier Transform Infrared (FTIR). Aulia (2017) membandingan metode koreksi pencaran Multiplicative Scatter Correction (MSC) dan Standard Normal Variate (SNV). Hasil yang diperoleh menunjukkan bahwa data yang dikoreksi menggunakan MSC dan SNV memiliki hasil yang relatif sama, tetapi dilihat dari kepraktisannya SNV lebih praktis dibandingkan dengan MSC karena SNV tidak perlu melakukan pemodelan. Namun, beberapa kasus sulit untuk mengidentifikasi pola kumpulan amatan yang ada, sehingga dibutuhkan suatu pendekatan nonparametrik untuk mengidentifikasi pola kumpulan amatan yang dimiliki. Aydin (2012) menyebutkan bahwa regresi Smoothing Spline memiliki kemampuan yang baik dalam mengidentifikasi bentuk kurva antara umur dan waktu bertahan hidup. Regresi Smoothing Spline merupakan salah satu metode nonparametrik bersifat piecewise polynomial, yaitu suatu potonganpotongan polinom yang memiliki sifat tersegmen pada selang $k$ yang terbentuk pada titik-titik knot Wang and Yang (2009). Hal ini berarti fungsi Spline merupakan suatu gabungan beberapa polynomial pada knot-knot dengan suatu cara yang menjamin sifat kontuitas. Sehingga hasil prapemrosesan yang diperoleh dapat lebih akurat.

Berdasarkan pertimbangan beberapa penelitian mengenai metode prapemrosesan, penelitian ini akan dilakukan teknik prapemrosesan Smoothing Spline untuk mengetahui pola hubungan spektrum keluaran alat pemantau kadar glukosa darah noninvasif.

\section{B. Tujuan}

Tujuan penelitian ini adalah melakukan metode prapemrosesan spektrum keluaran alat pemantau kadar glukosa darah non-invasif untuk mengurangi pengaruh inferensi gelombang dan noise menggunakan regresi nonparametrik Smoothing Spline serta menetapkan orde maupun jumlah knot terbaik bagi glukosa darah.

\section{TINJAUAN PUSTAKA}

\section{A. Alat Pemantau Kadar Glukosa Darah}

Alat pengukuran kadar glukosa darah adalah salah satu yang digunakan untuk mengetahui kadar glukosa dalam darah. Pengukuran kadar glukosa darah dapat dilakukan dengan metode invasif dan non-invasif. Pengukuran secara invasif dilakukan dengan melukai anggota tubuh menggunakan glukometer atau pemeriksaan laboratorium untuk diambil sampel darah. Glukometer (silver standard) merupakan alat ukur kadar glukosa darah yang beredar di pasaran. Setelah jari tangan dilukai dengan jarum tusuk, darah yang keluar dari jari tangan diteteskan ke strip tes yang selanjutnya diukur kadar glukosa darahnya menggunakan glukometer. Metode ini dinilai lebih cepat dan praktis, akan tetapi hasil pengukurannya kurang akurat. Pemeriksaan melalui tes laboratorium (gold standard) dilakukan secara kimiawi, yaitu dengan penambahan reagen pada volume tertentu. Pemeriksaan ini dilakukan dengan cara mengambil sampel darah sebanyak $4 \mathrm{~mL}$ pada pembuluh darah vena dari lengan. Hasil tes laboratorium sudah cukup akurat dan presisi, tetapi pengukuran ini membutuhkan proses preparasi yang lama dan reaksi kimiawi rawan terhadap interferensi Aulia (2017).

Pengukuran secara non-invasif dilakukan tanpa melukai anggota tubuh menggunakan alat pemantau kadar glukosa darah non-invasif. Pengukuran ini memanfaatkan fenomena optik berupa terjadinya penyerapan cahaya pada panjang gelombang spesifik gula darah atau disebut dengan spektroskopi yaitu memanfaatkan cahaya inframerah sebagai jenis radiasi yang digunakan. Alat ini mengukur kadar glukosa darah melalui jari tangan. Ketika jari tangan disinari oleh cahaya inframerah, sebagian intensitas cahaya ada yang diserap dan sebagian yang lain ada yang dilewatkan. Intensitas cahaya yang dilewatkan 
selanjutnya akan ditangkap oleh sensor dalam bentuk nilai tegangan analog yang bersifat kontinu. Setelah itu, nilai tegangan analog ditransformasi menjadi nilai tegangan digital yang bersifat diskret melalui Analog Digital Converter (ADC) karena server tidak dapat membaca nilai tegangan analog. Selanjutnya, server mengolah sinyal digital dengan algoritma Fast Fourier Transform (FFT) sehingga menghasilkan spektrum time domain terhadap intensitas yang ditampilkan melalui Liquid Crystal Display (LCD).

\section{B. Smoothing Spline}

Pemulusan Spline atau smoothing spline merupakan salah satu jenis teknik reduksi data yang digunakan dalam model kalibrasi. Pemulusan Spline ini memiliki fleksibilitas dalam melakukan pendugaan regresi dengan fungsi regresi dasar.

Spline merupakan fungsi berupa potongan polinomial yang memiliki ruas-ruas yang berbeda dan tersambung bersama pada titik-titik knot dengan syarat jaminan kekontinuan Gunawan (2001). Misalnya, terdapat $n$ pengamatan $\left(x_{i}, y_{i}\right)$ dengan $i=1,2, \ldots, n$ serta $x_{i}$ dan $y_{i}$ dalam $\mathrm{R}$. Variabel $x_{i}$ merupakan variabel independen time domain pada pengamatan ke- $i$, variabel dependen nilai intensitas pada pengamatan ke- $i$, dan $\mathrm{R}$ adalah bilangan riil. Secara umum model regresi nonparametrik dapat dinyatakan sebagai berikut :

$$
y_{i}=f\left(x_{i}\right)+\varepsilon_{i}, i=1,2, \ldots, n
$$

dengan $f\left(x_{i}\right)$ merupakan kurva regresi yang dihampiri dengan fungsi spline berorde $m$ dengan titik knot $k_{1}, k_{2}, \cdots, k_{r}$, yang diberikan oleh persamaan :

$$
f\left(x_{i}\right)=\sum_{j=0}^{m} \beta_{0} x_{i}{ }^{j}+\Sigma_{j=1}^{r} \beta_{m+j}\left(x_{i}-k_{j}\right)_{+}^{m}
$$

Keterangan:

$\beta_{0}:$ intersep;

$\beta_{m+j}$ : slope pada peubah $x$ truncated knot ke- $k$ pada spline berorde $m$;

$k_{j}:$ knot ke- $k$;

$r$ : banyaknya textitknot;

Titik knot dapat diartikan sebagai suatu titik fokus dalam fungsi spline sehingga kurva yang terbentuk tersegmen pada titik tersebut. Apabila persamaan (3) disubstitusikan ke persamaan (4) maka akan diperoleh persamaan (5), yang merupakan persamaaan regresi nonparametrik spline
Fungsi $\left(x_{i}-k_{j}\right)_{+}^{m}$ merupakan fungsi truncanted (potongan) yang diberikan oleh :

$$
\left(x_{i}-k_{j}\right)_{+}^{m}=\left\{\begin{array}{cll}
\left(x_{i}-k_{j}\right)^{m} & \text { untuk } & x_{i} \geq k_{j} \\
0 & \text { untuk } & x_{i}<k_{j}
\end{array}\right.
$$

dengan $m$ adalah orde spline dan $k$ adalah knot yang terpilih. Menurut Fahrmeir and Tuhtz (1994), untuk menduga kurva pemulus $f\left(\hat{x}_{i}\right)$ dengan $\varepsilon_{i}$ diasumsikan saling bebas, nilai tengah $f\left(x_{i}\right)$ nol, dan ragam $\sigma^{2}$, dapat diperoleh berdasarkan data amatan yaitu pasangan peubah penjelas dan peubah responnya. Estimasi titik fungsi $f$ diperoleh dengan meminimumkan fungsi Penalized Least Square (PLS) berikut :

$$
P L S=\sum_{i=1}^{n}\left(y_{i}-f\left(x_{i}\right)\right)^{2}+\lambda \int_{-\infty}^{\infty}\left[f^{\prime \prime}\left(x_{i}\right)\right]^{2} d x
$$

dimana bagian pertama merupakan jumlah kuadrat sisaan atau fungsi jarak antara data dan dugaan, bagian kedua merupakan Roughness Penalty, yaitu ukuran kemulusan kurva dalam memetakan data.

$$
y_{i}=\Sigma_{j=0}^{m} \beta_{0} x_{i}{ }^{j}+\Sigma_{j=1}^{r} \beta_{m+j}\left(x_{i}-k_{j}\right)_{+}^{m}+\varepsilon_{i}
$$

Menurut Eubank (1988) dalam Tripena (2011) menyebutkan bahwa ukuran kinerja atas penduga kurva regresi dapat ditentukan dari rataan kuadrat sisaan (MSE), fungsi loss, fungsi risiko, serta Generalized Cross Validation (GCV). Metode GCV merupakan metode yang paling sering digunakan, dalam pemilihan knot dengan melihat nilai GCV minimum, dengan rumus sebagai berikut :

$$
G C V(\lambda)=\frac{M S E(\lambda)}{\left(n^{-1} \operatorname{trace}[I-H]\right)^{2}}
$$

dengan $H=\left(x^{\prime} x\right)^{-1} x^{\prime}$ dan MSE (Mean Square Error) sebagai berikut :

$$
\operatorname{MSE}(\lambda)=n^{-1} \sum_{i=1}^{n}\left(y_{i}-f\left(x_{i}\right)\right)^{2}
$$

\section{METODOLOGI}

\section{A. Data}

Data yang digunakan dalam penelitian ini berupa data primer pengukuran kadar glukosa darah secara invasif berupa hasil pengukuran laboratorium 
dan hasil pengukuran kadar glukosa darah noninvasif. Penelitian inimerupakan penelitian Pengembangan dan Uji Klinis Purwarupa Alat Pemantau Kadar Glukosa Darah Non-Invasif pada Orang yang Berisiko Mengalami Gangguan Glikemik pada April 2016 Januari 2017 oleh Tim Non-Invasif Biomarking, Institut Pertanian Bogor (IPB). Penelitian ini didanai oleh Program Insentif Riset Sistem Inovasi Nasional, Kementerian Riset, Teknologi, dan Pendidikan Tinggi dengan melibatkan 118 responden sukarela yang merupakan mahsiswa dari beberapa departemen di IPB. Pelaksanaan penelitian bertempat di Laboratorium Bio Kimia, Departemen Gizi Masyarakat, IPB.

Pengambilan data kadar glukosa darah invasif dilakukan dengan mengambil sampel darah sebanyak $4 \mathrm{~mL}$ pada pembuluh darah vena dari lengan responden. Selanjutnya, sampel darah tersebut dibawa ke laboratorium untuk dilakukan pemeriksaan secara kimiawi.

Pengambilan hasil pengukuran alat pemantau kadar glukosa darah non-invasif berupa intensitas cahaya yang melewati jari tangan responden. Jari tangan yang digunakan adalah jari manis pada tangan kiri responden selama 20 detik, dengan ulangan sebanyak 5 kali secara berturut-turut. Masingmasing ulangan menghasilkan spektrum yang terdiri dari 10 periode waktu (time domain). Peubah time domain ini memungkinkan data yang dihasilkan pada setiap periode dan ulangan memiliki jumlah yang berbeda-beda.

\section{B. Prosedur Analisis Data}

Tahapan penelitian yang dilakukan adalah sebagai berikut :

1) Melakukan ekplorasi pada kumpulan amatan kadar glukosa darah invasif hasil pengukuran laboratorium dengan melihat diagram pencar dan diagram kotak garis dari seluruh responden terhadap kadar glukosa darah invasif.

2) Melakukan eksplorasi dan pra-proses pada kumpulan amatan hasil pengukuran alat pemantau kadar glukosa darah non-invasif dengan melihat diagram pencar dari tiap ulangan. Kemudian melakukan penyetaraan time domain.

3) Memilih tiga responden secara acak dengan kategori glukosa darah normal, pra-diabetes, dan diabetes berdasarkan hasil eksplorasi data hasil pengukuran glukosa darah invasif.

4) Spektrum dari nilai intensitas masing-masing ulangan di plot terhadap time domain untuk melihat pola garis di setiap ulangan dan periode.

5) Melakukan pemulusan menggunakan Smoothing Spline dengan orde satu, dua, dan tiga, serta menggunakan beberapa titik knot. Variabel $x$ yang digunakan adalah time domain dan nilai intensitas sebagai variabel $y$.

6) Memilih titik knot dan orde optimal berdasarkan nilai GCV yang paling minimum.

7) Mendapatkan hasil pemulusan untuk masingmasing responden spline dengan orde dan titik knot optimal.

8) Menghitung nilai keragaman sebagai tahap evaluasi hasil pemulusan.

\section{HASIL DAN PEMBAHASAN}

\section{A. Ekplorasi Data Kadar Glukosa Darah Invasif Hasil Pengukuran Laboratorium}

Tahap pertama yang dilakukan adalah eksplorasi kumpulan amatan dengan tujuan memudahkan dalam memilih responden yang akan dilakukan metode Smoothing Spline. Tahapan eksplorasi dilakukan dengan melihat plot diagram pencar dan diagram kotak garis dari kumpulan amatan kadar glukosa darah invasif pada 118 responden. Plot diagram pencar dan diagram kotak garis kadar glukosa darah invasif disajikan pada Gambar 1 dan Gambar 2.

Gambar 1, menunjukkan bahwa kumpulan amatan kadar glukosa darah invasif memiliki pola yang relatif konstan di sekitar $80 \mathrm{mg} / \mathrm{dL}$ dengan nilai amatan terkecil $67 \mathrm{mg} / \mathrm{dL}$ dan nilai amatan terbesar $276 \mathrm{mg} / \mathrm{dL}$. Hal ini menunjukkan bahwa kadar glukosa darah invasif pada penelitian kali ini secara umum memiliki rentang yang pendek dengan ratarata $82.64 \mathrm{mg} / \mathrm{dL}$ dan median $80 \mathrm{mg} / \mathrm{dL}$. Namun, terdapat satu amatan dengan kadar glukosa darah di atas normal yang terlihat sebagai nilai ekstrem, yaitu dengan kadar glukosa darah sebesar 276 mg/dL.

Responden yang akan dilakukan tahap prapemrosesan Smoothing Spline ditentukan dengan mencari responden dengan kadar glukosa darah terbesar dan terkecil. Hasil eksplorasi diperoleh responden 


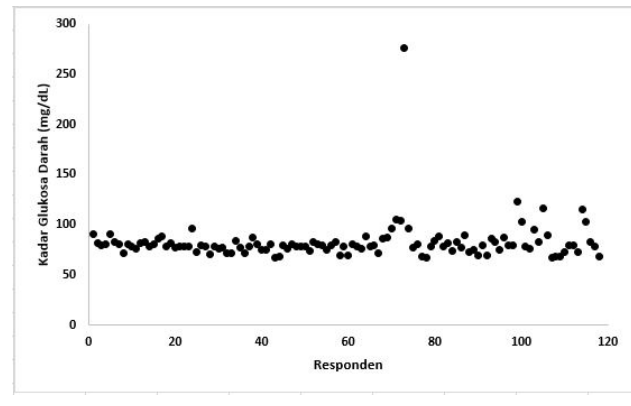

Gambar 1. Diagram pencar glukosa darah invasif

dengan kadar glukosa darah sebesar 276 mg/dL dan $67 \mathrm{mg} / \mathrm{dL}$.

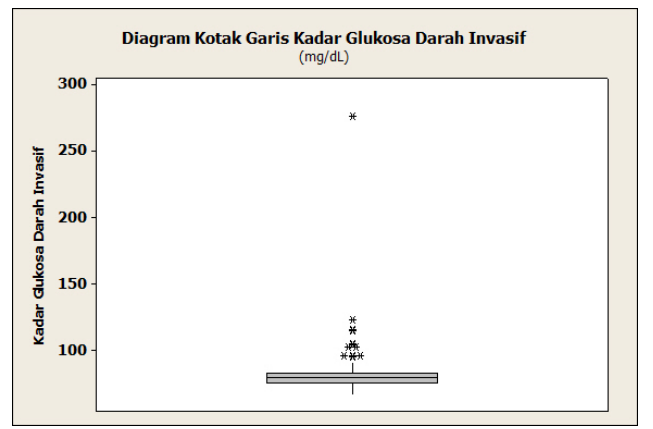

Gambar 2. Diagram kotak garis glukosa darah invasif

Gambar 2 menunjukkan bahwa terdapat beberapa data kadar glukosa darah yang diduga sebagai pencilan. Setelah diteliti lebih lanjut, ternyata terdapat 12 data yang merupakan pencilan. Terlepas dari 1 data yang terlihat sebagai nilai paling ekstrim yaitu kadar glukosa darah sebesar $276 \mathrm{mg} / \mathrm{dL}$, terdapat satu amatan yang dengan kategori pra-diabetes yaitu pada rentang 108-125 mg/dL yang dipilih secara acak diperoleh amatan dengan kadar glukosa 123 $\mathrm{mg} / \mathrm{dL}$. Oleh karena itu, selanjutnya pada penelitian ini diambil sampel sebanyak 3 responden. Responden yang terpilih yaitu responden dengan kadar glukosa darah terbesar pertama yaitu 276 $\mathrm{mg} / \mathrm{dL}$, kadar glukosa darah terbesar kedua yaitu $123 \mathrm{mg} / \mathrm{dL}$, serta kadar glukosa darah terkecil, yaitu $67 \mathrm{mg} / \mathrm{dL}$. Setelah itu, dilihat kumpulan amatan hasil pengukuran alat pemantau kadar glukosa darah non-invasif pada 3 responden tersebut untuk dilihat pola data spektrumnya serta dilakukan teknik prapemrosesan Smoothing Spline.

\section{B. Eksplorasi Data Hasil Pengukuran Alat Pen- gukur Kadar Glukosa Darah Non-Invasif}

Alat pemantau kadar glukosa darah non-invasif memanfaatkan suatu sensor dan cahaya inframerah. Saat cahaya inframerah ditembakkan ke jari tangan, sebagian intensitas diserap dan sebagian yang lain dilewatkan. Intensitas yang dilewatkan inilah yang terbaca oleh sensor. Kumpulan amatan intensitas dan time domain yang digunakan berasal dari sensor lampu dengan panjang gelombang $1600 \mathrm{~nm}$ pada periode 26 sampai dengan periode 30 . Hal ini disebabkan intensitas yang dipancarkan oleh sinar inframerah dapat terbaca dengan baik oleh sensor pada kelima periode waktu tersebut. Setiap periode memiliki jumlah intensitas dan time domain yang berbeda-beda. Ekplorasi ini dilakukan pada kumpulan amatan intensitas dan time domain dengan membuat plot time domain terhadap intensitas. Tujuan dilakukan eksplorasi ini untuk melihat pola yang dibentuk oleh setiap ulangan dan melihat pola pergeserannya. Pengukuran alat pemantau glukosa darah non-invasif untuk setiap responden menghasilkan lima ulangan. Hasil eksplorasi disajikan pada Gambar 3.
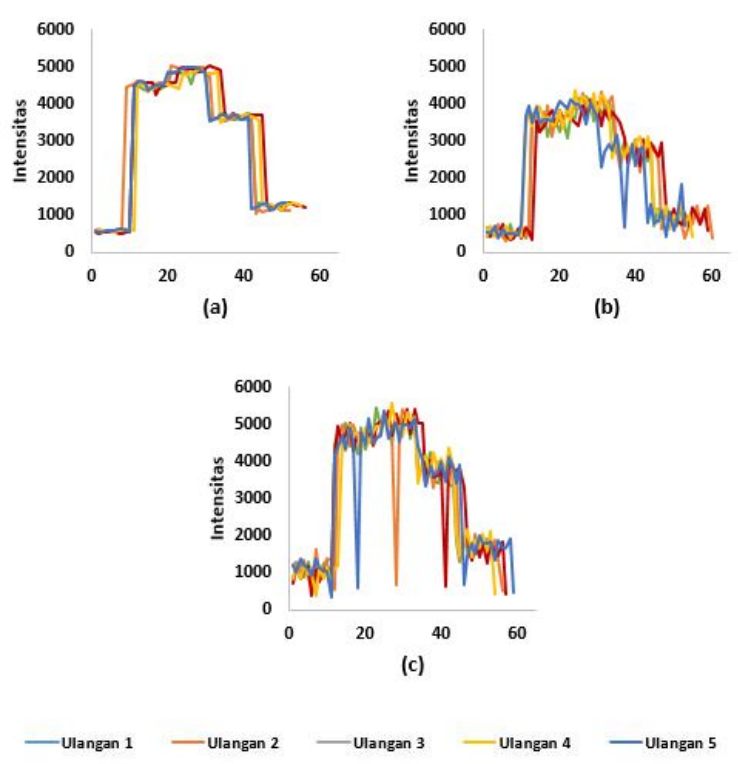

Gambar 3. Plot time domain terhadap intensitas kadar glukosa darah (a) $67 \mathrm{mg} / \mathrm{dL}$, (b) $123 \mathrm{mg} / \mathrm{dL}$, dan (c) $276 \mathrm{mg} / \mathrm{dL}$

Gambar 3 terlihat bahwa plot intensitas terhadap time domain dari ketiga responden menghasilkan pola yang berbeda-beda. Hal ini dapat disebabkan 
oleh adanya noise pada data hasil keluaran alat ukur glukosa darah. Plot yang dihasilkan oleh responden dengan kadar glukosa darah $67 \mathrm{mg} / \mathrm{dL}$ memiliki pola yang relatif sama untuk setiap ulangannya dibandingkan responden lainnya. Responden dengan kadar glukosa darah $123 \mathrm{mg} / \mathrm{dL}$ memiliki pola yang berbeda pada ulangan 5. Sementara itu, responden dengan kadar glukosa darah 276 mg/dL memiliki pola yang berbeda pada ulangan 2 , ulangan 3 , dan ulangan 5. Perbedaan pola pada setiap ulangan ini disebabkan adanya nilai ekstrem.

Secara umum, terlihat pada Gambar 3 pola yang terbentuk di setiap ulangan pada masing-masing responden mengalami pergeseran pergeseran amatan. Secara eksplorasi, pola pergeseran yang terlihat adalah pergeseran kiri-kanan. Responden dengan kadar glukosa darah $123 \mathrm{mg} / \mathrm{dL}$ dan $276 \mathrm{mg} / \mathrm{dL}$ memiliki pola pergeseran bawah-atas selain pergeseran kiri-kanan. Adanya pergeseran dan pola pembentukan yang berbeda dapat disebabkan oleh jumlah intensitas dan time domain yang berbeda. Oleh karena itu, perlu dilakukan penyetaraan time domain domain dan intensitas.
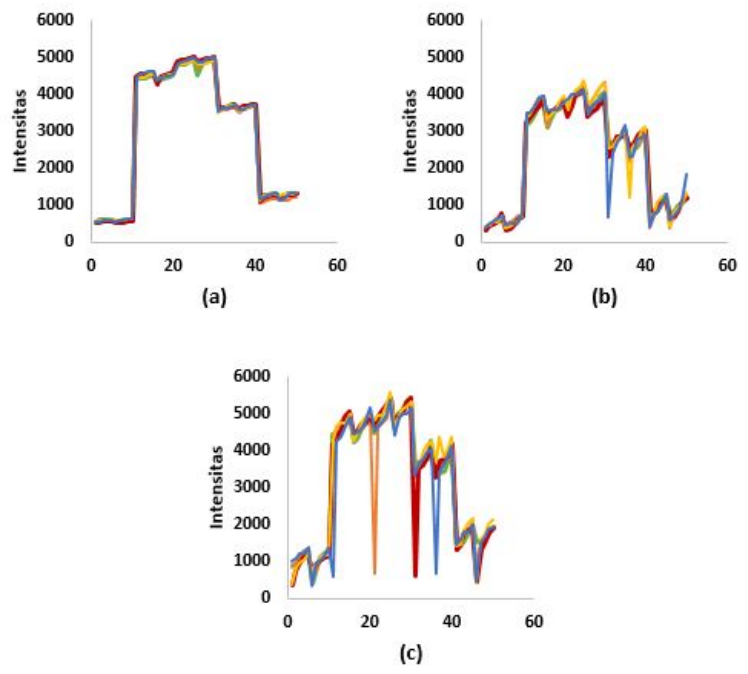

—Ulangan 1

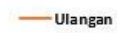

Gambar 4. Plot time domain terhadap intensitas kadar glukosa darah (a) $67 \mathrm{mg} / \mathrm{dL}$, (b) $123 \mathrm{mg} / \mathrm{dL}$, dan (c) $276 \mathrm{mg} / \mathrm{dL}$ hasil penyetaraan

Penyetaraan terhadap kumpulan amatan time domain dan intensitas ini dilakukan dengan metode peringkasan. Hasil penyetaraan terhadap time domain dan intensitas ditunjukkan oleh Gambar 4. Penyetaraan time domain dan intensitas yang di- hasilkan setelah tahap peringkasan, menunjukkan bahwa perubahan kumpulan amatan tidak signifikan. Secara eksplorasi terlihat masih adanya pergeseran percaran dan perbedaan pola amatan pada masingmasing ulangan untuk setiap responden. Responden dengan glukosa darah $67 \mathrm{mg} / \mathrm{dL}$ menghasilkan pola yang relatif sama untuk setiap ulangan. Responden dengan glukosa $123 \mathrm{mg} / \mathrm{dL}$ menghasilkan pola yang berbeda pada ulangan 4 dan 5, sedangkan responden dengan glukosa $276 \mathrm{mg} / \mathrm{dL}$ menghasilkan pola yang berbeda pada ulangan 2, 3, dan 5. Selanjutnya, dilakukan tahap prapemrosesan yaitu koreksi Smoothing Spline terhadap kumpulan amatan ini agar menghasilkan informasi yang sama sehingga dapat mengindentifikasi pola amatan kadar glukosa darah non-invasif ketiga responden tersebut.

\section{Penentuan Titik Knot}

Penentuan titik knot dapat dilakukan dengan beberapa cara, diantaranya adalah dengan membagi jarak antar knot sama besar, membagi jumlah amatan sama banyak, maupun menentukan posisi knot secara eksploratif sesuai dengan perubahan bentuk kurva. Penentuan posisi knot secara eksploratif merupakan cara yang paling efektif karena mengikuti perubahan garis regresi. Namun, pada data yang berjumlah besar akan lebih efektif jika menggunakan cara membagi jarak antar knot sama besar atau membagi jumlah amatan sama banyak karena akan mempercepat proses analisis. Penentuan posisi knot dengan ketiga cara tersebut dilakukan setelah peubah prediktor dan peubah respon diplotkan.

Pemilihan jumlah knot dapat dilakukan dengan melihat pola amatan yang akan dilakukan pemulusan maupun pendugaan. Terdapat dua cara untuk menentukan jumlah knot yang digunakan, yaitu menggunakan jumlah knot yang sedikit karena alasan kesederhanaan model atau menggunakan jumlah knot yang banyak. Penggunaan knot dengan jumlah yang banyak biasanya diterapkan pada kumpulan amatan dengan pola yang kompleks. Apabila dilihat dari Gambar 4, bentuk kurva dari masing-masing plot cukup sederhana sehingga tidak memerlukan jumlah knot yang banyak.

Posisi knot yang dihasilkan akan menjadi titik potong dari amatan yang akan di regresi. Orde yang dicobakan pada tiap responden adalah orde 1 
(linear), 2 (kuadratik), dan orde 3 (kubik) dengan jumlah knot yang dicobakan sebanyak dua puluh titik knot. Pemotongan knot yang dihasilkan akan menjadi titik potong dari data yang akan di regresi namun tetap dalam satu model.

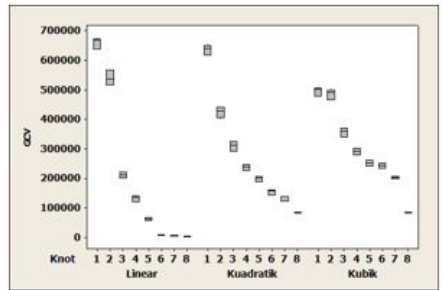

(a)

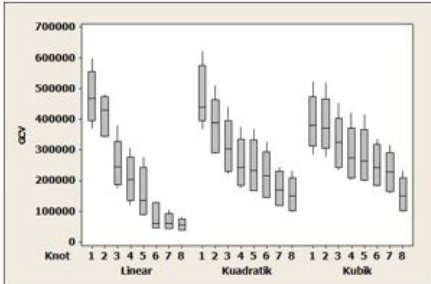

(b)

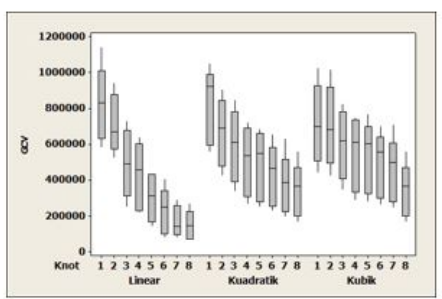

(c)

Gambar 5. Diagram kotak garis nilai GCV dengan 8 knot pada glukosa darah (a) $67 \mathrm{mg} / \mathrm{dL}$, (b) $123 \mathrm{mg} / \mathrm{dL}$, dan (c) $276 \mathrm{mg} / \mathrm{dL}$

Gambar 5, terlihat bahwa responden $67 \mathrm{mg} / \mathrm{dL}$ mengalami perubahan nilai GCV yang cukup drastis seiring pertambahan jumlah knot untuk setiap orde, dengan tingkat keragaman nilai yang rendah. Nilai GCV menurun seiring penambahan jumlah knot yang digunakan. Rata-rata nilai GCV orde linear, kuadratik, dan kubik untuk semua titik knot berturut-turut pada responden $67 \mathrm{mg} / \mathrm{dL}$ sebesar 203237.6, 272240.2, dan 301596.7. Sama halnya seperti responden dengan glukosa darah $67 \mathrm{mg} / \mathrm{dL}$, responden dengan glukosa $123 \mathrm{mg} / \mathrm{dL}$ dan 276 $\mathrm{mg} / \mathrm{dL}$ menunjukkan perubahan nilai GCV seiring pertambahan jumlah knot untuk setiap orde, namun dengan tingkat keragaman nilai yang relatif lebih tinggi dibandingkan responden dengan glukosa 67 $\mathrm{mg} / \mathrm{dL}$. Penggunaan orde dua (kuadratik) dan tiga (kubik) untuk responden $123 \mathrm{mg} / \mathrm{dL}$ dan $276 \mathrm{mg} / \mathrm{dL}$ memiliki pola dan keragaman yang mirip, sehingga perubahan yang mencolok terlihat pada penggunaan orde satu (linear) dengan pola semakin curam seiring penambahan jumlah knot. Rata-rata nilai GCV orde linear, kuadratik, dan kubik berturutturut pada responden $123 \mathrm{mg} / \mathrm{dL}$ sebesar 214659.6, 277514.8, dan 287639.7. Rata-rata nilai GCV orde linear, kuadratik, dan kubik berturut-turut pada responden $276 \mathrm{mg} / \mathrm{dL}$ sebesar 411776.4, 521599, dan 546500.7. Dapat disimpulkan untuk setiap responden berdasarkan nilai rata-rata keseluruhan titik knot, diperoleh nilai GCV minimum pada orde satu (linear). Jika dilihat berdasarkan nilai GCV di setiap knot, diperoleh nilai GCV minimum pada penggunaan delapan titik knot. Hal ini berlaku di semua penggunaan orde. Nilai GCV minimum dengan delapan titik knot disajikan pada Tabel 1.

Tabel I

RATA-RATA NILAI GCV MINIMUM PADA MASING-MASING ORDE MENGGUNAKAN DELAPAN KNOT

\begin{tabular}{cccc}
\hline \multirow{2}{*}{ Responden } & \multicolumn{3}{c}{ Rata-rata Nilai GCV } \\
& Linear & Kuadratik & Kubik \\
\hline $67 \mathrm{mg} / \mathrm{dL}$ & $\mathbf{4 1 3 6 . 9 5}$ & 84744 & 140679 \\
$123 \mathrm{mg} / \mathrm{dL}$ & $\mathbf{5 6 5 6 1}$ & 154747 & 194546 \\
$276 \mathrm{mg} / \mathrm{dL}$ & $\mathbf{1 4 6 2 7 8}$ & 339440 & 411959 \\
\hline
\end{tabular}

Tabel 1 menunjukkan bahwa pada nilai GCV minimum, yaitu dengan delapan titik knot dihasilkan pada orde linear. Oleh karena itu, akan dikaji lebih lanjut penggunaan orde satu (linear) pada data kadar glukosa darah dengan menambahkan jumlah knot yang digunakan sampai dengan dua puluh knot. Banyaknya knot yang digunakan pada kasus ini dirasa sudah cukup karena plot nilai kadar glukosa darah non-invasif data aktual tidak kompleks.

Tabel II

NilAi GCV MINIMUM PADA 16 KNOT

\begin{tabular}{cccccccc}
\hline Responden & \multicolumn{6}{c}{ Nilai GCV pada Setiap Ulangan } & Rata-rata \\
& 1 & 2 & 3 & 4 & 5 & \\
\hline $67 \mathrm{mg} / \mathrm{dL}$ & 1401.5 & 975.6 & 1373.2 & 453.1 & 1536.4 & 1147.9 \\
& & & & & & \\
$123 \mathrm{mg} / \mathrm{dL}$ & 5029.9 & 9207.7 & 10668.0 & 27418.1 & 39208.3 & 18306.0 \\
& & & & & & \\
$276 \mathrm{mg} / \mathrm{dL}$ & 22239.9 & 168344.3 & 89847.1 & 48540.4 & 149035.7 & 95601.5
\end{tabular}

Tabel 2 menunjukkan nilai GCV untuk masingmasing responden dengan orde linear dan knot optimum. Nilai GCV semakin rendah maka semakin optimum hasil pemulusan yang diperoleh.

\section{Hasil Pemulusan Smoothing Spline dengan Knot Optimum}

Hasil pemulusan dengan metode Smoothing Spline pada spektrum menunjukkan hasil yang 
cukup baik dalam menangkap pola data spektrum aslinya. Plot intensitas terhadap time domain hasil Smoothing Spline ditampilkan pada Gambar 6.
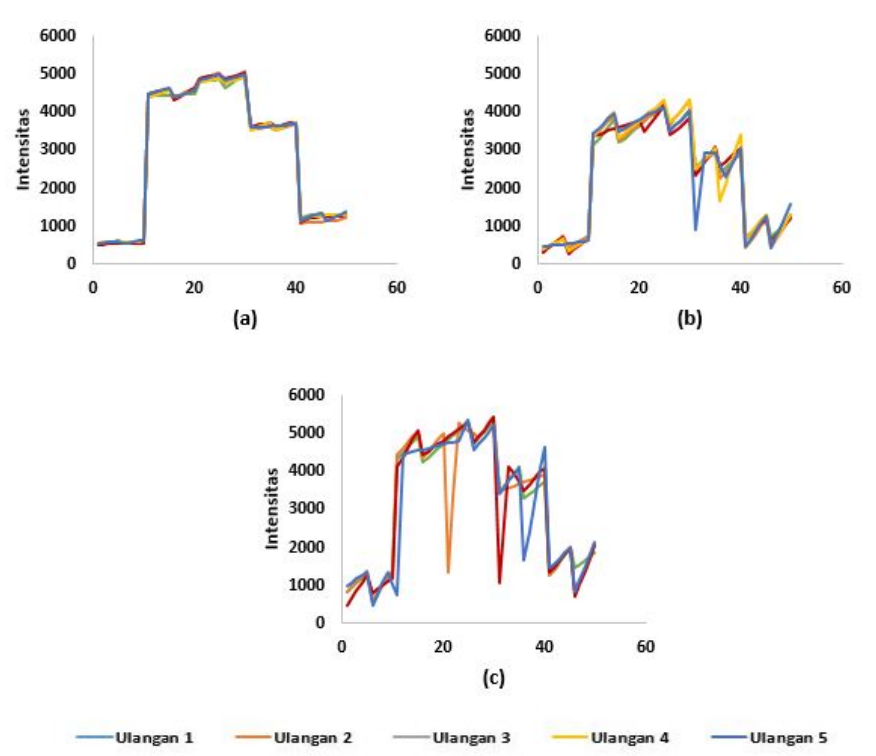

Gambar 6. Plot time domain terhadap intensitas dengan 16 knot pada glukosa darah (a) $67 \mathrm{mg} / \mathrm{dL}$, (b) $123 \mathrm{mg} / \mathrm{dL}$, dan (c) $276 \mathrm{mg} / \mathrm{dL}$

Gambar 6 menunjukkan bahwa plot untuk setiap ulangan pada masing-masing responden mampu menghasilkan pola mendekati pola data aslinya. Responden dengan kadar glukosa darah 123 mg/dL memiliki pola data yang berbeda pada ulangan 4 dan 5 mengindikasikan adanya pengaruh nilai ekstrem. Namun, setelah dilakukan Smoothing Spline, pola data pada ulangan 4 dan 5 semakin ditarik ke atas mendekati plot ulangan-ulangan lainnya. Sedangkan responden dengan kadar glukosa darah $276 \mathrm{mg} / \mathrm{dL}$ memiliki pola data yang berbeda pada ulangan 2 , 3, dan 5 karena adanya pengaruh nilai ekstrem. Namun, sama halnya seperti pada responden dengan kadar glukosa darah $123 \mathrm{mg} / \mathrm{dL}$ ulangan 2, 3, dan 5 ditarik ke atas mendekati plot ulangan lainnya. Selanjutnya, dilihat nilai keragaman data sebelum dan setelah dilakukan Smoothing Spline.

Metode pemulusan dengan Smoothing Spline menghasilkan pola data yang sudah cukup bisa menangkap pola data kadar glukosa darah untuk masing masing responden dengan baik. Terlihat pada nilai keragaman kadar glukosa darah awal mengalami penurunan setelah dilakukan pemulusan Smoothing Spline. Responden dengan kadar glukosa darah 67 mg/dL menghasilkan nilai keragaman sete-
Tabel III

HASIL PERBANDINGAN KERAGAMAN ANTARA DATA AWAL DAN SETELAH DILAKUKAN SMOOTHING SPLINE

\begin{tabular}{ccc}
\hline Kadar Glukosa Darah & Awal & Smoothing \\
\hline $67 \mathrm{mg} / \mathrm{dL}$ & 2151.17 & $\mathbf{2 1 5 1 . 6 2}$ \\
$123 \mathrm{mg} / \mathrm{dL}$ & 25367.50 & $\mathbf{2 2 0 4 5 . 2 0}$ \\
$276 \mathrm{mg} / \mathrm{dL}$ & 165745.00 & $\mathbf{1 4 9 8 9 6 . 0 0}$ \\
\hline
\end{tabular}

lah smoothing lebih besar daripada nilai keragaman awal sebelum dilakukan smoothing. Hal ini tidak begitu berarti karena selisih antara nilai keragaman awal dan setelah smoothing hanya 0.5 Hasil smoothing yang dihasilkan tetap bisa menangkap pola data dengan baik. Responden dengan kadar glukosa darah $123 \mathrm{mg} / \mathrm{dL}$ diperoleh nilai keragaman yang lebih kecil setelah dilakukan smoothing meskipun perbedaan nilainya tidak terlalu signifikan. Begitu pula pada responden dengan kadar glukosa darah $276 \mathrm{mg} / \mathrm{dL}$, nilai keragaman yang dihasilkan setelah dilakukan smoothing lebih kecil. Hal ini dapat diindikasikan bahwa teknik prapemrosesan Smoothing Spline ini cukup mampu meminimalisir pengaruh pencaran dari spektrum keluaran alat pemantau kadar glukosa darah non-invasif. Nilai keragaman yang dihasilkan sebelum dan setelah dilakukan pemulusan cukup besar karena data yang intensitas memiliki skala yang besar untuk setiap observasi.

\section{SIMPULAN}

Teknik prapemrosesan data menggunakan metode Smoothing Spline menghasilkan plot yang cukup baik dalam menangkap pola data aktual. Berdasarkan nilai GCV rata-rata untuk setiap ulangan diperoleh nilai GCV minimum pada hasil smoothing dengan orde linear dan enam belas titik knot. Metode ini juga terbukti dapat meminimalisir pengaruh pencaran (noise) yang dihasilkan oleh spektrum keluaran alat pemantau kadar glukosa darah non-invasif. Hal ini dibuktikan dari nilai keragaman yang diperoleh setelah dilakukan tahap prapemrosesan Smoothing Spline lebih rendah dari nilai keragaman data sebelum Smoothing Spline.

\section{DAFTAR PUSTAKA}

Arnita (2005). Koreksi pencaran dalam model kalibrasi peubah ganda pada data senyawa aktif 
gingerol serbuk rimpang jahe (zingeber officinale roscue).

Aulia, W. (2017). Koreksi pencaran pada data hasil pengukuran alat pemantau kadar glukosa darah non-invasif.

Aydin, D. (2012). A comparison of the nonparametric regression models using smoothing spline and kernel regression. World Academy of Science, Engineering and Technology 36, 253-257.

Blanco, M., J. Coello, H. Iturriaga, S. Maspoch, and C. de la Pezuela (1998). Near-infrared spectroscopy in the pharmaceutical industry. Appl Spectrosc 123, 135-150.

Cen, H. and Y. He (2007). Theory and application of near infrared reflectance spectroscopy in determination of food quality. Trends in Food Science and Technology 18, 72-83.

Fahrmeir, L. and G. Tuhtz (1994). Multivariate Statistical Modelling Based on Generalized Linier Models. New York: Springer-Verlag.

Gunawan, A. (2001). Studi penggunaan pemulusan spline pada regresi nonparametrik.

Hruschka, W. (1987). Data analysis: Wavelength selection methods. Data analysis: Wavelength selection methods, 35-56.

Tripena, A. (2011). Pemilihan parameter penghalus dalam regresi spline linier. JMP 3.

Wang, J. and L. Yang (2009). Polynomial spline confidence bands for regression curves. Statistica Sinica 19, 325-342. 